\title{
Comparisons Between the Squash Bug Egg Parasitoids Ooencyrtus anasae and $O$. sp. (Hymenoptera: Encyrtidae): Development, Survival, and Sex Ratio in Relation to Temperature
}

\author{
J. L. TRACY AND J. R. NECHOLS \\ Department of Entomology, Kansas State University, \\ Manhattan, Kansas 66506
}

\begin{abstract}
Environ. Entomol. 16(6): 1324-1329 (1987)
ABSTRACT Laboratory investigations of the gregarious squash bug egg parasitoids Ooencyrtus anasae and $O$. n. sp. near anasae (O. sp.) were conducted at $20.8,23.0$, and $26.6^{\circ} \mathrm{C}$. In both species, total developmental periods (egg to eclosed adult) were inversely related to temperature. Temperature had no significant influence on survivorship, progeny production, or sex ratio. At each temperature, $O$. anasae developed and emerged about a day earlier and produced a significantly higher percentage of female progeny $(77 \%)$ than did $O$. sp. $(60 \%)$. Both parasitoids deposited an average of three $(2-7)$ progeny per host. However, $O$. anasae consistently deposited more female eggs per host than did $O$. sp. Proportion of females produced per host by $O$. anasae tended to increase directly with number of hosts parasitized but no such relationship was observed in $O$. sp. Total preimaginal survivorship in both parasitoids was about $89 \%$. In $O$. sp., male progeny that developed without females emerged about a day later at all temperatures and had a lower pharate adult survivorship than did males that developed in hosts with female siblings.
\end{abstract}

KEY WORDS Insecta, Anasa tristis, gregarious parasitoids, biological control

EVALUATION OF natural enemy attributes is of central importance to their proper utilization in biological control programs (DeBach et al. 1976, Ehler 1982, Ehler \& Hall 1982). Comparative evaluations of closely related beneficial species are particularly useful because they form the basis for examining complex interactions, selecting candidates for massrearing and release in augmentation programs (Messenger et al. 1976, King et al. 1985), and investigating the biosystematics of poorly understood taxa, including many of the parasitic Hymenoptera (Delucchi et al. 1976, Gordh 1976).

The squash bug (SB), Anasa tristis (DeGeer) (Hemiptera: Coreidae), is a serious native pest of cucurbitaceous crops throughout the Midwest and much of North America (Nechols 1987). Although several hymenopterous egg parasitoids occur naturally on the SB in eastern Kansas (unpublished data), the biology or ecology of this egg parasitoid complex have not been investigated. Therefore, we have begun a comprehensive evaluation of two of the most common, gregarious encyrtids-Ooencyrtus anasae (Ashmead) and a new, closely related species, Ooencyrtus sp. near anasae (hereafter, $O$. sp.) (Gordon Gordh, personal communication). $O$. sp. lacks dark patches on its femora, thus distinguishing it from $O$. anasae (Ashmead 1887). Voucher specimens of both species are deposited at Kansas State University.

In this study, we compare several biological attributes of $O$. anasae and $O$. sp. at various tem- peratures. Specifically, our objectives were to determine, for each species, total developmental period (egg to free-living adult), number of progeny produced, preimaginal survivorship, and sex ratio. We also examined the distribution of male and female progeny among individual host eggs.

\section{Materials and Methods}

Insect Cultures. Our SB colony originated from overwintered adults that were field-collected during May and June 1985. Nymphs and adults were reared in cages under a photoperiod of 16:8 (L:D) at ca. $27^{\circ} \mathrm{C}$ on potted 'Green Zucchini' and 'Early Prolific Straightneck' squash (Cucurbita pepo L. [Harris Seed Co., Rochester, N.Y.]). Illumination was provided by Aluorescent lamps (Cool White).

Parasitoid colonies were initiated in July 1985 by collecting adults and parasitized SB egg masses from zucchini and pumpkin fields near Manhattan, Kans. Newly emerged adults were sorted to species, placed in cages, then transferred to environmental growth chambers under a photoperiod of 15:9 (L:D) and $26.6^{\circ} \mathrm{C}$. Plastic boxes that contained a saturated $\mathrm{NaCl}$ solution were used to maintain about $75 \% \mathrm{RH}$. Both colonies were supplied continuously with moist cotton and a $40 \%(v / v)$ honey-water solution for food. SB egg masses ( $\leq 1 \mathrm{~d}$ old) were added every other day.

Parasitization. To obtain parasitized hosts, individual pairs (female and male) of first- or second- 
Table 1. Mean ( $\pm S D$ ) number of days for total preimaginal development in the gregarious SB egg parasitoids, $O$. anasae and $O$. sp., under the indicated temperatures

\begin{tabular}{|c|c|c|c|}
\hline \multirow{3}{*}{$\begin{array}{c}\text { Tempe } \\
\left({ }^{\circ} \mathrm{C}\right)\end{array}$} & \multicolumn{3}{|c|}{ Total developmental time (egg to eclosed adult) } \\
\hline & \multirow{2}{*}{$\frac{\text { O. anasae }}{89+\infty 8}$} & \multicolumn{2}{|c|}{ O. sp. } \\
\hline & & $\$ 9+\delta 8$ & $\delta \delta$ \\
\hline 20.8 & $\begin{array}{c}31.9 \pm 0.7 \\
(38)\end{array}$ & $\begin{array}{c}33.3 \pm 1.0 \\
(26)\end{array}$ & $\begin{array}{c}34.5 \pm 0.6 \\
(15)\end{array}$ \\
\hline 23.0 & $\begin{array}{c}24.5 \pm 1.3 \\
(33)\end{array}$ & $25.1 \pm 0.8$ & $\begin{array}{c}26.9 \pm 1.1 \\
(17)\end{array}$ \\
\hline 26.6 & $18.0 \pm 1.0$ & $19.0 \pm 0.6$ & $\begin{array}{c}19.6 \pm 0.7 \\
(21)\end{array}$ \\
\hline
\end{tabular}

$a(n)$, number of parasitized hosts.

" All paris of means are significantly different $(P<0.05$; FPLSD). 15:9 (L:D)

laboratory-generation parasitoids ( $\leq 12 \mathrm{~h}$ old) were transferred to shell vials that contained honey-water and single clusters of five to six $\mathrm{SB}$ eggs $(\leq 24 \mathrm{~h}$ old), then placed under one of the experimental temperature conditions (Table 1). Average temperature fluctuations were $<0.5^{\circ} \mathrm{C}$ in all experiments. Parasitoid males were removed on the second day, and host eggs were replaced with fresh egg clusters daily until parasitization ceased.

After exposure, we examined host eggs with a dissecting microscope $(70 \times)$ and counted the number of egg stalks left by the parasitoid on the exterior of each host (see Maple [1937] for description). Each egg stalk represents at least one parasitoid egg within the host. Some parasitized hosts were then placed individually into wells of tissue culture plates and held under the same conditions as the parental parasitoids. Others were dissected to determine the relationship between the number of egg stalks and the number of eggs per host. This relationship was used to estimate the total number of parasitoid eggs laid per treatment $\left(N_{\mathrm{e}}\right)$ (see Survivorship).

Development and Progeny Production. Parasitoid emergence was checked daily. We computed the total developmental period as the number of days from parasitization to adult eclosion. Because parasitoids within a single host egg emerged synchronously, the data were pooled for all emergence from the same host. A high percentage of $O$. sp. females did not mate and produced only male progeny (unpublished data). Therefore, we recorded the data separately for all-male progeny.

We used a two-way ANOVA and Fisher's protected least-significant-difference test (FPLSD) (SAS Institute 1985) to test for the effects of species, temperature, and the presence or absence of females in the host on mean developmental times and on the number of progeny emerging per host. The progeny data were natural log-transformed before analysis.

Survivorship. Total survivorship (egg to adult) was computed as the number of emerged parasitoids $\left(N_{\mathrm{a}}\right)$ divided by $N_{\mathrm{e}}$. Similarly, survivorship through the egg-larval stage was calculated as the number of individuals reaching the pharate adult stage $\left(N_{p}\right)$ divided by $N_{\mathrm{e}}$. We determined $N_{\mathrm{p}}$ by counting the number of emerged and unemerged adults from each host. Survivorship through the pharate adult stage was calculated as $N_{\mathrm{a}} / N_{\mathrm{p}}$. Survivorship values were converted to percentages and examined for species and temperature effects by a functional analysis for categorical variables (FUNCAT procedure; SAS Institute [1985]). Hosts that bore only one stalk were omitted from analysis because of high variance in the associated number of parasitoid eggs.

Sex Ratio. We recorded numbers of females and males that emerged from individual hosts and converted them to the percentage of females. We tested the arcsine-transformed data (Snedecor \& Cochran 1980) for species and temperature effects by a twoway analysis of covariance (ANCOVA) (using the number of parasitoids per host as a covariate) and by FPLSD. We used the same analysis to test for the effects of species and survivorship (ca. 60 or $90 \%$ ) on the per host sex ratio. In the survivorship analyses, sex ratios were compared between host groups where parasitoid survivorship was the lowest (ca. 60\%) and the highest (ca. 90\%).

Distribution of Progeny per Host. We counted the number and sex of adult parasitoids emerging from individual hosts in which parasitoid survivorship exceeded $90 \%$ (i.e., experienced little or no mortality). From these counts we obtained estimates of the number of progeny and sex ratio per host. These data were pooled over all temperatures and analyzed for species effects. We also tested for the effects of the number of hosts each female parasitized per parasitization day, and the number of eggs laid per host. We analyzed the natural logtransformed progeny data by a two-way ANOVA, and the arcsine-transformed sex ratio data by a two-way ANCOVA. Percentages of hosts receiving no males, and differing numbers of parasitoid eggs, were analyzed by the FUNCAT procedure.

\section{Results}

Development. The total developmental periods of both parasitoid species were inversely related to temperature, and ranged from ca. $18 \mathrm{~d}$ at $26.6^{\circ} \mathrm{C}$ to ca. $32 \mathrm{~d}$ at $20.8^{\circ} \mathrm{C}$ (Table 1). Preimaginal development in $O$. anasae was significantly $(P<0.05$ FPLSD) shorter at each temperature than in $O$. sp.

Male parasitoids that developed without females (all-male progeny) had significantly $(P<0.05$; FPLSD) longer developmental times at all temperatures than did conspecific males that developed and emerged synchronously with female siblings from the same host (Table 1).

Progeny Production. The number of parasitoids that emerged per host egg did not vary significantly with temperature or parasitoid species $(P>0.43$; ANOVA). O. anasae produced $3.1 \pm 0.9(\bar{x} \pm \mathrm{SD})$ $(n=122)$ offspring per host compared to $3.1 \pm 0.7$ 
Table 2. The percentage of total and stage-specific survivorship in the gregarious SB egg parasitoids, $O$. anasae and $o$. sp., at the indicated temperatures

\begin{tabular}{|c|c|c|c|c|c|c|c|c|c|}
\hline \multirow{4}{*}{$\begin{array}{c}\text { Temp }^{b} \\
\left({ }^{\circ} \mathrm{C}\right)\end{array}$} & \multicolumn{9}{|c|}{$\%$ survivorship ${ }^{a}$} \\
\hline & \multicolumn{3}{|c|}{ Total (egg to adult eclosion) } & \multicolumn{3}{|c|}{ Egg-larval } & \multicolumn{3}{|c|}{ Pharate adult } \\
\hline & \multirow{2}{*}{$\frac{O . \text { anasae }}{\$ 8+}$} & \multicolumn{2}{|c|}{ O. sp. } & \multirow{2}{*}{ 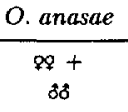 } & \multicolumn{2}{|c|}{$O . \mathrm{sp}$} & \multirow{2}{*}{ 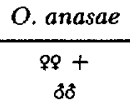 } & \multicolumn{2}{|c|}{$O$. sp. } \\
\hline & & $\begin{array}{c}98+ \\
8 \delta\end{array}$ & 20 & & $\begin{array}{c}98+ \\
88\end{array}$ & ¿̊̊ & & $88+$ & $\delta \delta$ \\
\hline 20.8 & $\begin{array}{c}90 a \\
(113: 12)\end{array}$ & $\begin{array}{l}89 a \\
(78: 10)\end{array}$ & $\begin{array}{l}75 b \\
(46: 16)\end{array}$ & $\begin{array}{c}90 a \\
(113: 12)\end{array}$ & $\begin{array}{c}89 a \\
(78: 0)\end{array}$ & $\begin{array}{l}82 \mathrm{a} \\
(51: 11)\end{array}$ & $\begin{array}{c}100 a \\
(113: 0)\end{array}$ & $\begin{array}{l}100 \mathrm{a} \\
(78: 0)\end{array}$ & $\begin{array}{l}90 \mathrm{a} \\
(46: 5)\end{array}$ \\
\hline 23.0 & $\begin{array}{c}91 \mathrm{a} \\
(125: 12)\end{array}$ & $\begin{array}{l}88 \mathrm{a} \\
(61: 6)\end{array}$ & $\begin{array}{l}84 \mathrm{~b} \\
(97: 18)\end{array}$ & $\begin{array}{c}91 \mathrm{la} \\
(125: 12)\end{array}$ & $\begin{array}{c}88 \mathrm{a} \\
(61: 9)\end{array}$ & $\begin{array}{c}90 \mathrm{a} \\
(103: 12)\end{array}$ & $\begin{array}{c}100 \mathrm{a} \\
(125: 0)\end{array}$ & $\begin{array}{l}100 \mathrm{a} \\
(61: 0)\end{array}$ & $\begin{array}{c}94 \mathrm{a} \\
(97: 6)\end{array}$ \\
\hline 26.6 & $\begin{array}{c}88 \mathrm{a} \\
(143: 19)\end{array}$ & $\begin{array}{l}86 a \\
(69: 11)\end{array}$ & $\begin{array}{l}87 \mathrm{~b} \\
(86: 13)\end{array}$ & $\begin{array}{c}90 \mathrm{a} \\
(145: 17)\end{array}$ & $\begin{array}{l}86 a \\
(69: 11)\end{array}$ & $\begin{array}{l}87 a \\
(86: 13)\end{array}$ & $\begin{array}{c}99 a \\
(143: 2)\end{array}$ & $\begin{array}{l}100 \mathrm{a} \\
(69: 0)\end{array}$ & $\begin{array}{l}100 \mathrm{a} \\
(86: 0)\end{array}$ \\
\hline
\end{tabular}

${ }^{a}(n: n)$, number of parasitoids surviving through stage/number of parasitoids dying during stage. Frequencies within rows or between columns followed by a different letter are significantly different $(P<0.05$; FUNCAT)

${ }^{b} 15: 9$ (L:D).

$(n=68)$ in $O$. sp. All progeny from the same egg emerged synchronously, usually through a common exit hole that was chewed by a female.

In $O$. sp., the number of all-male progeny produced per host $(3.3 \pm 0.7[n=70])$ did not differ statistically from that found in hosts containing females (i.e., "mixed-sex" progeny).

Survivorship. We found the following numerical relationship between the number of egg stalks protruding from the host and the number of parasitoid eggs within the host: 1 stalk, $2.1 \pm 1.1$ eggs (158) eggs $(\bar{x} \pm \mathrm{SD}[n]) ; 2$ stalks, $2.8 \pm 1.0(78)$; 3 stalks, $3.2 \pm 0.5$ eggs ( 46$) ; 4$ stalks, $4.4 \pm 0.8$ eggs (7).

Total survivorship (egg to emerged adult) was high (range, $86-91 \%$ ) in both species, and it did not vary with temperature (Table 2 ). In the mixedsex progeny of both species, the small amount of mortality was associated almost entirely with the egg-larval stages. In $O$. sp., pharate adult survivorship for all-male progeny was relatively lower at 20.8 and $23.0^{\circ} \mathrm{C}$ (range, $90-94 \%$ ) than that of mixed-sex progeny (100\%) (Table 2). A significantly $(P<0.05$; FUNCAT) lower total survivorship was also observed for all-male progeny at these temperatures (Table 2).

Sex Ratio. O. anasae produced a significantly $(P<0.05$; FPLSD) higher proportion of female progeny per host at each temperature than $\operatorname{did} O$. sp. (Table 3). The per-host sex ratios were not significantly affected by either temperature or preimaginal survivorship. Overall, $O$. anasae produced $77 \%(n=346)$ females compared with $60 \%$ $(n=216)$ for $O$. sp.

Distribution of Progeny per Host. There was no apparent relationship between the number of eggs deposited per host and the total number of hosts parasitized per female per day for either species (Table 4, column A). However, in O. anasae, the percentage of female progeny per host tended to increase as the number of hosts parasitized increased (Table 4, columns B and C). This relationship was not observed in $O$. sp.
The percentage of hosts receiving two, three, four, or five to seven parasitoid eggs was similar for both species (Table 5), with most host eggs receiving three parasitoid eggs. However, for any given number of parasitoid progeny per host, $O$. anasae produced a significantly $(P<0.05 ;$ FPLSD) higher percentage of females per host than $\operatorname{did} O$. sp. (Table 5).

\section{Discussion}

Development. The total developmental period of $O$. anasae was slightly, but significantly, shorter than that of $O$. sp. at each of the three temperatures. Because both species are multivoltine, these differences may be ecologically meaningful over the course of a season. For example, although the limited number of temperature conditions precludes estimation of the thermal requirements for each species, the available developmental data suggest that $O$. anasae has a smaller thermal constant.

Table 3. Influence of temperature and survivorship on the percentage of emerged females for the gregarious SB egg parasitoids, $O$. anasae and $O$. sp.

\begin{tabular}{lcc}
\hline \hline & \multicolumn{2}{c}{ \% emerged females per host, } \\
& \multicolumn{2}{c}{ O. anasae } \\
\cline { 2 - 3 } & & O. sp. \\
\hline Temp $\left({ }^{\circ} \mathrm{C}\right)^{b}$ & & \\
20.8 & $71.1 \pm 25.3(39) \mathrm{a}$ & $63.9 \pm 23.7(24) \mathrm{b}$ \\
23.0 & $75.8 \pm 25.8(32) \mathrm{a}$ & $66.8 \pm 24.8(21) \mathrm{b}$ \\
26.6 & $81.8 \pm 16.1(31) \mathrm{a}$ & $55.6 \pm 17.7(21) \mathrm{b}$ \\
\% survivorship & & \\
High (91-92\%) & $79.2 \pm 21.5(92) \mathrm{a}$ & $61.5 \pm 21.1(54) \mathrm{b}$ \\
Low (62-63\%) & $68.3 \pm 33.7(10) \mathrm{a}$ & $65.2 \pm 28.8(12) \mathrm{b}$ \\
\hline
\end{tabular}

"Number of parent females per temperature were as follows: $O$. anasae, 11-13; 0 . sp., 4-6. For survivorship analysis, data are combined for all temperatures. Means followed by a different letter are significantly different $(P<0.05 ;$ FPLSD).

$b_{15: 9}$ (L:D) 
Table 4. Relationship between the number of hosts parasitized per day and the number and sex of progeny deposited per host for the gregarious SB egg parasitoids, $O$. anasae and $O$. sp. ${ }^{a b c}$

\begin{tabular}{|c|c|c|c|c|c|c|}
\hline \multirow{2}{*}{$\begin{array}{l}\text { No. hosts } \\
\text { parasitized } \\
\text { in } 24 \mathrm{~h}\end{array}$} & \multicolumn{2}{|c|}{$\begin{array}{c}(A) \\
\text { No. parasitoid eggs per host, } \\
\bar{x} \pm \operatorname{SD}(n)\end{array}$} & \multicolumn{2}{|c|}{$\begin{array}{c}(B) \\
\% \text { emerged } \% q \text { per host, } \\
\bar{x} \pm S D(n)\end{array}$} & \multicolumn{2}{|c|}{$\begin{array}{l}(\mathrm{C}) \\
\% \text { of hosts producing only } \$ 2 \\
\text { (no. without } ₫ 8 / \text { no. with } ₫ 8)\end{array}$} \\
\hline & O. anasae & O. sp. & O. anasae & O. sp. & O. anasae & $O . \mathbf{s p}$ \\
\hline 1 & $\frac{3.7 \pm 0.7 a}{(29)}$ & $\begin{array}{c}3.2 \pm 0.8 \mathrm{a} \\
(12)\end{array}$ & $\begin{array}{c}76.3 \pm 10.6 a \\
(29)\end{array}$ & $67.1 \pm 25.6 b$ & $\begin{array}{c}14 a \\
(4: 25)\end{array}$ & $\begin{array}{c}20 \mathrm{~b} \\
(2: 10)\end{array}$ \\
\hline 2 & $3.4 \pm 0.8 \mathrm{a}$ & $\begin{array}{c}3.3 \pm 0.7 a \\
(12)\end{array}$ & $\begin{array}{c}70.5 \pm 32.7 a \\
(40)\end{array}$ & $61.7 \underset{(12)}{ \pm} 9.4 b$ & $\begin{array}{c}33 \mathrm{a} \\
(13: 27)\end{array}$ & $\begin{array}{c}0 \mathrm{~b} \\
(0: 12)\end{array}$ \\
\hline 3 & $\frac{3.5 \pm 1.2 \mathrm{a}}{(30)}$ & $3.3 \underset{(20)}{ \pm 1.0 \mathrm{a}}$ & $80.0 \pm 18.9 a$ & $62.1 \pm 21.1 b$ & $\begin{array}{c}34 \mathbf{a} \\
(11: 21)\end{array}$ & $\begin{array}{c}10 \mathrm{~b} \\
(2: 18)\end{array}$ \\
\hline 4 & $\frac{3.0 \pm 0.8 a}{(36)}$ & $\begin{array}{c}2.9 \pm 0.7 a \\
(10)\end{array}$ & $86.0 \pm \underset{(36)}{15.3 a}$ & $53.3 \pm 25.8 b$ & $\begin{array}{c}53 \mathrm{a} \\
(19: 17)\end{array}$ & $\begin{array}{r}20 \mathrm{~b} \\
(2: 8)\end{array}$ \\
\hline 5 & $3.1 \pm 0.7 a$ & - & $84.2 \pm 16.5 a$ & - & $\begin{array}{c}50 \\
(11: 17)\end{array}$ & - \\
\hline
\end{tabular}

D Data are combined for all temperatures, including two additional conditions, 21.8 and $25.6^{\circ} \mathrm{C}$.

${ }^{b}$ For a given variable, means or frequency percentages followed by a different letter are significantly different $(P<0.05$; FPLSD for means and FUNCAT for frequency percentages).

c $15: 9$ (L:D).

In $O$. sp., all-male progeny took significantly longer to emerge at all temperatures than did conspecific males that developed and emerged synchronously with females (Table 1). Our observations show that females are generally larger than males, and they typically produce the common exit hole from which both sexes emerge. Thus, delayed male emergence when no female is present may result from a longer time required for males to chew through the host egg chorion. This explanation is supported by our finding that pharate adult survivorship in $O$. sp. was reduced at lower temperatures, but only in hosts that contained no females (Table 2). The number of parasitoids was similar in hosts that contained all males and those with at least one female; thus, competition had no apparent influence on emergence times.

Table 5. Percentage of SB hosts and percentage of parasitoid females per host in relation to number of parasitoid eggs per host for $O$. anasae and $O$. sp. The data are combined for all temperatures

\begin{tabular}{|c|c|c|c|c|}
\hline \multirow{2}{*}{$\begin{array}{c}\text { No. } \\
\text { para- } \\
\text { sitoid } \\
\text { eggs per } \\
\text { host }\end{array}$} & \multicolumn{2}{|c|}{$\begin{array}{c}\% \text { of hosts in } \\
\text { each category }\end{array}$} & \multicolumn{2}{|c|}{$\begin{array}{c}\text { \% females per host, } \\
\bar{x} \pm \operatorname{SD}(n)^{c}\end{array}$} \\
\hline & $\begin{array}{c}O . \\
\text { anasae }\end{array}$ & O. sp. & O. anasae & $O . \mathrm{sp}$ \\
\hline 2 & $\begin{array}{c}16 \\
(15)\end{array}$ & $\begin{array}{l}13 \\
(7)\end{array}$ & $\begin{array}{l}95.7 \pm 20.9 \mathrm{a} \\
(23)\end{array}$ & $57.1 \pm 45.0 \mathrm{~b}$ \\
\hline 3 & $\begin{array}{c}54 \\
(51)\end{array}$ & $\begin{array}{c}65 \\
(35)\end{array}$ & $\begin{array}{c}78.1 \pm 21.9 \mathrm{c} \\
(79)\end{array}$ & $67.7 \pm 11.4 \mathrm{~d}$ \\
\hline 4 & $\begin{array}{c}28 \\
(23)\end{array}$ & $\begin{array}{l}17 \\
(9)\end{array}$ & $\underset{(45)}{71.1 \pm 19.9 c}$ & $47.2 \pm 19.5 d$ \\
\hline $5-7$ & $\begin{array}{c}6 \\
(5)\end{array}$ & $\begin{array}{l}5 \\
(3)\end{array}$ & $\begin{array}{l}81.6 \pm 9.7 \mathrm{c} \\
(10)\end{array}$ & $54.3 \pm 22.3 d$ \\
\hline
\end{tabular}

${ }^{a}$ Differences in percentages between species are not significant.

" $(n)$, number of parasitized hosts.

" Percentages followed by a different letter are significantly different $(P<0.05 ;$ FPLSD $)$.
Progeny Production. Both $O$. anasae and $O$. sp. are gregarious parasitoids whose progeny emerge synchronously from the host. Gregarious development occurs in several other species of Ooencyrtus (Maple 1937, Matteson 1981, Fedde 1982), and synchronous emergence has been reported for a wide range of gregarious endoparasitoids (Nechols 1981, Fedde 1982, Narasimham 1984, Nechols \& Kikuchi 1985, Arakaki \& Ganaha 1986).

Our observations reveal that both $O$. anasae and $O$. sp. mate very soon after emergence in the laboratory (unpublished data). Thus, synchronous emergence may facilitate mating with siblings ("sib mating"). Sib mating may represent an important adaptive strategy for female parasitoids when host densities are low, because eggs can be fertilized before females disperse to locate new hosts (Arakaki \& Ganaha 1986).

Survivorship. Total preimaginal survivorship for mixed-sex progeny was high in both parasitoids at all three temperatures (Table 2). However, this survivorship is slightly lower than that reported by Fedde (1982) under similar conditions for Ooencyrtus trinidadensis Crawford, an egg parasitoid of the coreid, Leptoglossus corculus (Say). In that species, survivorship per host ranged from 92 to $100 \%$ between 21 and $27^{\circ} \mathrm{C}$ and $76 \% \mathrm{RH}$.

Sex Ratio. In our study, differential survivorship of the sexes did not appear to influence interspecific differences in sex ratios (Table 3). And, although other factors may have produced the observed differences in sex ratios (e.g., see Werren et al. [1986]), our observations indicate that the most important factor was probably species-specific differences in the regulation of oocyte fertilization (i.e., sex ratio regulation) by the female parasitoids. Sex ratio regulation is a well known phenomenon among arrhenotokous parasitic Hymenoptera (Flanders 1956). 
The percentages of female parasitoids that emerged from field-collected SB eggs in 1985 and 1986 were $77 \%(n=278)$ in $O$. anasae and $60 \%$ $(n=111)$ in $O$. sp. These values are the same as the overall percentage of females we found in these parasitoids in the laboratory. Therefore, the factors that regulate sex ratio in the field may be similar to those that occur in the laboratory.

Distribution of Progeny per Host. In our study, the frequency distribution of the number of parasitoid progeny deposited per host was similar for both species. However, O. anasae produced a consistently higher percentage of female progeny per host than did $O$. sp. for any given number of progeny deposited (Table 5). The occurrence of these differences under uniform conditions of host age and number suggests that interspecific differences in sex-ratio regulation exist (see discussion above).

As the number of hosts parasitized per cluster increased, $O$. anasae tended to produce a higher percentage of females and to deposit only female progeny in a progressively higher percentage of hosts (Table 4). Although these trends were not significant, they appear to support recent data for the egg parasitoid Trichogramma evanescens Westwood, which showed that male progeny are usually deposited in the first few hosts parasitized in a cluster ("patch") (Waage \& Ng 1984). Our results agree also with their model, which assumes that the minimum number of males are produced to mate with all sibling females within a localized area (i.e., "patch"). Males of the solitary gypsy moth egg parasitoid, Ooencyrtus kuvanae (Howard), will mate with females emerging from the same egg cluster prior to dispersal in the field (Brown 1984). This behavior may also occur among siblings of gregarious species like $O$. anasae and O. sp.

$O$. anasae produced the highest percentage of female progeny when the fewest eggs (i.e., two) were deposited per host (Table 5). A similar trend was observed for Ooencyrtus patriciae Subba Rao by Matteson (1981), who suggested that this oviposition behavior increases fitness by allowing females to develop with a greater food supply. Thus, larger females with higher fecundities can be produced.

In contrast to $O$. anasae, there was no apparent relationship between the per-host sex ratio in $O$. $\mathrm{sp}$. and the number of hosts parasitized per cluster (Table 4) or the number of eggs deposited per host (Table 5). Although we have not established hostspecies preferences for $O$. sp., these results may indicate that $O$. sp. is less adapted to hosts that occur in clusters than is $O$. anasae. Or, like the stink bug egg parasitoid, Ooencyrtus telenomicida Vassiliev, they may deposit more males in nonpreferred than in preferred hosts (Kotchetova 1977).

Alternatively, the relatively greater proportion of males produced by $O$. sp. may be associated with differences in mating behavior between the two species. In the laboratory, a much higher pro- portion of $O$. sp. females remain unmated when paired with a single male than do $O$. anasae (unpublished data).

Although we cannot fully evaluate the potential of these two indigenous parasitoids for biological control of SB on the basis of our present findings, interspecific differences in development and sex ratio regulation indicate that $O$. anasae may be a more efficient species to use in a mass-rearing program.

\section{Acknowledgment}

We thank B. J. Willcutts and C. Armendariz (Kansas State University [KSU]) for technical help. We also thank G. Gordh (University of California, Riverside) for taxonomic assistance. We appreciate the thoughtful suggestions made on an earlier draft of this paper by $\mathrm{M}$. J. Tauber and C. A. Tauber (Cornell University), D. C. Margolies and E. A. Vogt (KSU), and two anonymous reviewers. We thank J. Higgins, J. Boyer, J. Crabb, and J. Pontius (KSU) for statistical assistance. This research was supported by Kansas Agricultural Experiment Station Hatch Project 546. This is contribution No. 87-319-J from the Kansas Agricultural Experiment Station.

\section{References Cited}

Arakaki, N. \& Y. Ganaha. 1986. Emergence pattern and mating behavior of Apanteles flavipes (Cameron) (Hymenoptera: Braconidae). Appl. Entomol. Zool. 3: $382-388$.

Ashmead, W. H. 1887. Insects affecting the squash, pp. 22-24. In U.S. Dep. Agric., Div. Entomology, Bull. 14.

Brown, M. W. 1984. Literature review of Ooencyrtus kuvanae (Hymenoptera: Encyrtidae), an egg parasite of Lymantria dispar (Lepidoptera: Lymantriidae). Entomophaga 29: 249-265.

DeBach, P., C. B. Huffaker \& A. W. Macphee. 1976. Evaluation of the impact of natural enemies, pp. 255282. In C. B. Huffaker \& P. S. Messenger [eds.], Theory and practice of biological control. Academic, New York.

Delucchi, V., D. R. Rosen \& E. I. Schlinger. 1976. Relationship of systematics to biological control, pp. 81-91. In C. B. Huffaker \& P. S. Messenger [eds.], Theory and practice of biological control. Academic, New York.

Ehler, L. E. 1982. Foreign exploration in California. Environ. Entomol. 11: 525-530.

Ehler, L. E. \& R. W. Hall. 1982. Evidence for competitive exclusion of introduced natural enemies in biological control. Environ. Entomol. 11: 1-4.

Fedde, V. H. 1982. Bionomics of the Caribbean bug egg parasite, Ooencyrtus trinidadensis Crawford (Hymenoptera: Encyrtidae). Ph.D. dissertation, North Carolina State Univ., Raleigh.

Flanders, S. E. 1956. The mechanisms of sex ratio regulation in the (parasitic) Hymenoptera. Insectes Soc. 3: 325-334.

Gordh, G. 1976. Biosystematics of natural enemies, pp. 125-148. In R. L. Ridgeway \& S. B. Vinson [eds.], Biological control by augmentation of natural enemies. Plenum, New York.

King, E. G., K. R. Hopper \& J. E. Powell. 1985. Analysis of systems for biological control of crop ar- 
thropod pests in the U.S. by augmentation of predators and parasites, pp. 201-227. In M. A. Hoy \& D. C. Herzog [eds.], Biological control in agricultural IPM systems. Academic, New York.

Kolchetova, N. I. 1977. Factors determining the sex ratio in some entomophagous Hymenoptera. Entomol. Rev. (English translation Entomol. Obozr.) 56: $1-5$.

Maple, J. D. 1937. The biology of Ooencyrtus johnsoni (Howard), and the role of the egg shell in the respiration of certain encyrtid larvae (Hymenoptera). Ann. Entomol. Soc. Am. 30: 123-154.

Matteson, P. C. 1981. Egg parasitoids of hemipteran pests of cowpea in Nigeria and Tanzania, with special reference to Ooencyrtus patriciae Subba Rao (Hymenoptera: Encyrtidae) attacking Clavigralla tomentosicollis Stål (Hemiptera: Coreidae). Bull. Entomol. Res. 71: 547-554.

Messenger, P. S., F. Wilson \& M. J. Whitten. 1976. Variation, fitness, and adaptability of natural enemies, pp. 209-227. In C. B. Huffaker \& P.S. Messenger [eds.], Theory and practice of biological control. Academic, New York.

Narasimham, A. U. 1984. Comparative studies on Tetrastichus hagenowii (Ratzeburg) and T. asthenogmus (Waterston), two primary parasites of cockroach oothecae, and on their hyperparasite Tetrastichtss sp. (T. miser (Nees) group) (Hymenoptera: Eulophidae). Bull. Entomol. Res. 74: 175-189.
Nechols, J. R. 1981. The environmental regulation of host-parasite synchrony between the cereal leaf beetle, Oulema melanopus (L.) (Coleoptera: Chrysomelidae) and its parasite Tetrastichus julis (Walker) (Hymenoptera: Eulophidae). Ph.D. dissertation, Cornell Univ., Ithaca.

1987. Voltinism, seasonal reproduction, and diapause in the squash bug (Heteroptera: Coreidae) in Kansas. Environ. Entomol. 16: 269-273.

Nechols, J. R. \& R. S. Kikuchi. 1985. Host selection of the spherical mealybug (Homoptera: Pseudococcidae) by Anagyrus indicus (Hymenoptera: Encyrtidae): influence of host stage on parasitoid oviposition, development, sex ratio, and survival. Environ. Entomol. 14: 32-37.

SAS Institute. 1985. SAS user's guide: statistics. SAS Institute, Cary, N.C.

Snedecor, C. W. \& W. C. Cochran. 1980. Statistical methods. Iowa State Univ., Ames.

Waage, J. K. \& S. M. Ng. 1984. The reproductive strategy of a parasitic wasp. I. Optimal progeny and sex allocation in Trichogramma evanescens. J. Anim. Ecol. 53: 401-415.

Werren, J. H., S. W. Skinner \& A. M. Huger. 1986. Male-killing bacteria in a parasitic wasp. Science 231 : 990-992.

Received for publication 19 February 1987; accepted 13 August 1987. 